\title{
Epistemologia/Epistolografia: notas para uma crítica
}

\author{
Epistemology/Epistolography: notes for a critique \\ Francine Carla de Salles Cunha Rojas* \\ * Universidade Federal de Mato Grosso do Sul, UFMS, Campo Grande - MS, 79070- \\ 900, e-mail: lucia_jbc@hotmail.com \\ Ricardo Magalhães Bulhões** \\ *** Universidade Federal de Mato Grosso do Sul, UFMS, Campo Grande - MS, 79070- \\ 900, e-mail: ricardoufms1@gmail.com
}

\begin{abstract}
RESUMO: A presente explanação desenvolve-se a partir das (MIGNOLO, 2003) cartas publicadas do escritor mineiro Fernando Sabino: Cartas na mesa (2002), Cartas a um jovem escritor e suas respostas (2003) e Cartas perto do coração (2011). Lidas em conjunto e de forma linear as cartas são (des)locadas de seu lócus (abstrato) original, isto é, o espaço intimo da convivência com os amigos. Tal fato já indica relevante característica do texto epistolar sinalizado no título da explanação, "pensamento nômade", trata-se de uma metáfora fornecida por Brigitte Diaz em seu livro O gênero epistolar ou o pensamento nômade (2016) e que evoca, de forma apropriada, a natureza andarilha das cartas. Uma outra metáfora necessária e que transcende o texto é a das "teorias itinerantes" (MIGNOLO, 2003), sua presença justifica-se ao provocar reflexões em torno da teorização epistolográfica, visto que várias teorias já viajaram por cartas, como a psicanalise, fato que Jacques Derrida em Mal de arquivo (2001) menciona, e as considerações modernistas presente nas cartas de intelectuais como Mário de Andrade. Mas, e a teoria da carta? Terá ela viajado através do texto epistolar? Ou então foi forçada a, tal como um intruso, viajar a reboque nos espaços liminares da teorias européias? Ou, então, sua viajem foi inviabilizada justamente por ser "teoria" e não teorização?. Leitura essencialmente metafórica está envolta nas considerações de Walter Mignolo em Histórias locais/projetos globais (2003) acerca da dupla natureza da fronteira, geográfica e epistemológica, a fim de sustentar que a teorização epistolar nasce a partir das fronteiras.
\end{abstract}

PALAVRAS-CHAVE: epistemologia; cartas; fronteiras.

ABSTRACT: The present explanation develops from (MIGNOLO, 2003) published letters of the mining writer Fernando Sabino: Letters in the table (2002), Letters to a young writer and its answers (2003) and Letters close to the heart (2011). Read together and linearly the letters are (un) leased from their original (abstract) locus, that is, the intimate space of coexistence with friends. This fact already indicates relevant characteristic of the epistolary text signaled in the title of the explanation, "nomadic thinking", it is a metaphor provided by Brigitte Diaz in his book The epistolary genre or the nomadic thought (2016) and that evokes, in an appropriate way, The wanderer nature of the cards. Another necessary metaphor that transcends the text is that of "itinerant theories" (MIGNOLO, 2003), its presence is justified by provoking reflections on epistemological theorizing, since

Volume 18

Número 40 
several theories have already traveled by letters, such as psychoanalysis, fact Which Jacques Derrida in Mal de archivo (2001) mentions, and the modernist considerations present in the letters of intellectuals as Mário de Andrade. But what about chart theory? Has she traveled through the epistolary text? Or was she forced, like an intruder, to travel in the limelight of European theories? Or, then, his journey was made unfeasible precisely because it was "theory" and not theorization ?. Essentially metaphorical reading is shrouded in the considerations of Walter Mignolo in Local Histories / Global Projects (2003) about the dual nature of the frontier, geographic and epistemological, in order to sustain that epistolary theorizing is born from the frontiers.

KEYWORDS: Epistemology; letters; frontiers.

\section{I - AS FRONTEIRAS DO PENSAMENTO NÔMADE: (i/e)mergir ${ }^{1}$ para a teorização epistolográfica}

A presente discussão é concebida a partir das cartas publicadas do escritor mineiro Fernando Sabino em três volumes Cartas a um jovem escritor e suas respostas (2003), Cartas na mesa (2002) e Cartas perto do coração (2011). A questão central a ser desenvolvida reside em delinear uma teorização epistolográfica pautada pelo princípio de que as cartas são, a todo momento, confrontadas com inúmeras fronteiras ao mesmo tempo em que com elas convivem.

A diferença basilar da proposta está em que pretende ser não uma teoria da carta, mas sim uma teorização epistolográfica. A distinção que as separa é ressaltada por Walter Mignolo quando, em Histórias locais/projetos globais (2003), explica que a primeira trata de "[...] uma mercadoria acadêmica (da mesma forma que as teorias pós-modernas estão sendo mercantilizadas)" (MIGNOLO, 2003, p. 146) que se restringe a observar, impondo determinada distancia vista como apropriada para métodos científicos. Já a segunda abrange a vivencia do crítico e: “[...] não se restringe a academia, e muito menos à academia norte americana" (MIGNOLO, 2003, p. 146).

Erigir a teorização das cartas ao invés de tecer uma teoria envolve a consideração de elementos como o lócus a partir do qual as cartas são escritas e que, considerando as correspondências de Sabino, muitas vezes carregam traços de outros lugares pelos quais o escritor mineiro passou. Aliado a essa questão paira a "natureza" das cartas, à dizer, a de que são constantemente (des)locadas, isto é, movem-se por meio da instituição postal,

\footnotetext{
${ }^{1}$ Os parênteses presentes no título não aparecem ao acaso uma vez que é a partir deles que a explanação teórica se desenvolve. O jogo de sentido engendrado pela linguagem ocorre pela aproximação das palavras “imergir" e "emergir" que, apesar da semelhança constitutiva, abrangem sentidos antagônicos.

Volume 18

Número 40
} 
para em seguida repousar em seus destinos e reiniciarem o ciclo quando lidas, e se, publicadas.

Da explanação de Mignolo ainda me interessa suas considerações acerca do conceito de fronteira, ou antes, os conceitos, dado que o crítico argentino se detém na dupla acepção da palavra, geográfica e epistemológica. Sua explanação possui como objetivo ressaltar que os saberes produzidos são cerceados e que, ainda que "viajem" sob a forma de "teorias itinerantes", trazem consigo marcas das fronteiras que as atravessam.

Nesse sentido, a relação das cartas com as fronteiras é regida pelos constantes deslocamentos a que são submetidas os textos. A essência dessa associação é sintetizada pelo fato de que as cartas são submetidas ao lócus geográfico, isto é, são escritas em meio a um determinado lugar. O que se questiona é: para a empreitada proposta quais são os elementos que devem ser considerados? Somente o lócus de origem (remetente)? Ou o lócus destinatário? E o que dizer do tempo? A relação entre carta e tempo se resume a datação que o texto epistolar carrega em seu corpo?

Tais questionamentos apontam que o caminho para a teorização epistolográfica assume, de modo metafórico, o mesmo mecanismo que é parte vital das cartas, as viagens, os deslocamentos, essa inconstância assimilada que (des)loca as correspondências dos tempos e lugares, embaralhando categorias rígidas. Em outras palavras, teorizar acerca das cartas segue o curso da errância, da viajem sem fim, afinal de um objeto itinerante somente poderia ser originado uma teorização itinerante. Do contrário incorreria em uma forma de leitura que separa teoria e prática.

Seja pelo fato de que são escritos originalmente para transporem grandes distâncias geográficas (de um país a outro, por exemplo), seja por ora serem concebidas para vencerem distâncias mais "modestas", como as relações pessoais (a exemplo de Carta ao pai de Franz Kafka), as correspondências amalgamam limites simultaneamente quando deles procuram se distanciar.

As constantes aproximações e distanciamentos, longe de anularem umas às outras, são o principal componente da escrita epistolar como estratégia de convivência com o destinatário. Pensar uma em face da outra exige-se o emprego do raciocínio substitutivo e metafórico da crítica biográfica, como proposto por Eneida Maria de Souza em Janelas indiscretas (2011):

No que diz respeito à abordagem mais pontual da crítica biográfica, é preciso distinguir e condensar os polos da arte e da vida, por meio do emprego do raciocínio substitutivo e metafórico, com vistas a não 
neutralizar e a reduzir os acontecimentos vivenciados pelo escritor (SOUZA, 2011, p. 21).

Para se pensar a relação das cartas com as fronteiras foram eleitas duas metáforas que, cada uma sua maneira, consigam a tríade fronteira - distância - aproximação: "pensamento nômade" e "teorias itinerantes". A primeira foi fornecida pelos apontamento de Brigitte Diaz em O gênero epistolar ou o pensamento nômade (2016) visto que a crítica francesa pontua que: “As cartas são textos híbridos e rebeldes a quaisquer identificações genéricas. Gênero literário indefinível, flutuam entre categorias vagas: arquivos, documentos, testemunhos" (DIAZ, 2016, 11).

A metáfora de Diaz é relevante, pois se atenta para a natureza textual das correspondências, a sua hibridização. Entretanto, para tecer a teorização, faz-se necessário considerar o contexto histórico. Avança-se tal discussão a partir da segunda metáfora, "teoria itinerantes" (MIGNOLO, 2003), que referem-se as teorias que, ao saírem do lócus em que inicialmente foram concebidas, viajam pelas e através das fronteiras.

Mas, pensar as cartas como teoria itinerantes suscita uma questão primordial: sabe-se que várias são as teorias que viajaram por carta, a exemplo da teoria psicanalítica como bem pontua Jacques Derrida em Mal de arquivo e as considerações do modernismo que encontra na produção epistolográfica de Mário de Andrade seu maior expoente, o que é discutido é se a própria teoria da carta viajou pela escrita epistolar ou se, por um caminho inesperado, tornou-se fugitiva e invasora, acabando por viajar clandestinamente e a reboque nas correspondências? Dessa forma a proposição da explanação defende que a teorização epistolográfica emergirá a partir da imersão nas fronteiras com as quais se depara.

Como documentos situados em um determinado tempo e lugar, as correspondências nutrem relação com a fronteira geográfica a ponto de ser afirmado que as ultrapassa. Tal "verdade" é interpelada quando constatado que as cartas carregam sinais de seu lugar de origem e os levam para seu destino "contaminando-o". Nesse sentido, a "fronteira" é diluída e a escrita epistolar é utilizada como uma forma de aproximação e de afastamento entre remetente e destinatário.

A questão em torno da fronteira geográfica ecoa no campo epistemológico visto ser a correspondência texto inicialmente lido como documento. Mas que quando considerado a intervenção de outros fatores, como o ensaio e a crônica nas cartas (Sabino exercera por muitos anos a função de cronista), a "verdade epistolar" é posta em jugo 
assim como os parâmetros que a delimitam, o que faz com que as cartas, ainda que preservem algo de si, incorporem características alheias.

As fronteiras, geográficas e epistemológicas, são o espaço por excelência em que as diferenças e as semelhanças emergem. Campo de aproximações e de distanciamentos, convergência e divergência, cuja constituição é esfumaçada. Sabe-se que existem, mas contorna-la é tão impreciso quanto apontar onde, de fato, residem.

A proposta desenvolvida, portanto, está sintetizada no título: “As fronteiras do pensamento nômade: (i/e)mergir para a teorização epistolográfica”, visto que, desde já, demonstra a consciência de que apesar de sua característica nômade, as cartas carregam as fronteiras dentro de si, sejam as epistemológicas, geográficas, textuais e/ou temporais. Imergir nelas é tão necessário quanto delas emergir, pois o nascimento da teorização epistolográfica funda-se a partir das fronteiras e de seus espaços liminares.

\section{II - O AQUÉM TEÓRICO, O ALÉM DA ESCRITA}

Uma fronteira não é o ponto onde algo termina, mas, como os gregos reconheceram, a fronteira é o ponto a partir do qual algo começa a se fazer presente.

HEIDEGGER apud BHABHA, 2013, p. 19.

O mestre, os amigos, a amiga. O epistolário de Fernando Sabino encobre sua vida e sua literatura "envelopando", por meio da escrita, pessoas, acontecimentos e épocas. Os volumes de correspondências publicadas e pelo escritor organizadas somam um total de quatro livros, sendo eles: Cartas a um jovem escritor (1981), Cartas a um jovem escritor e suas respostas (2003), Cartas na mesa (2002) e Cartas perto do coração (2001). De modo que a soma desses papeis, antes avulsos, e agora encadernados ajudam a contar uma história.

As cartas que compõem cada volume, ainda que escritas pela mesma pessoas, se situam em lugares diferentes na narrativa da vida de Fernando Sabino, isto é, os lugares a partir dos quais foram escritas são diferentes, os destinatários são diversos e, nesse caso, muda-se o destinatário e a forma de se escrever, os assuntos são variados assim como o tamanho de cada missiva, em alguns casos assumindo a forma de um breve bilhete, em outros momentos sendo de grande extensão.

A afinidade eletiva pelas cartas do escritor mineiro, dentro do universo epistolar na Literatura Brasileira, advém da percepção de que tais cartas, ainda que escritas pelo 
mesmo autor, são diferentes entre si, tal fato tem como contrapartida a forma pela qual o escritor efetua tal mudança, de quais estratégias se vale para vislumbrar o destinatário.

Entendo que as mudanças mencionadas são, de um lado, de natureza textual, mas também percebo que o texto, enquanto estrutura linguística, não é de todo responsável pelo fenômeno. Por conseguinte, a leitura empreendida parte da hipótese de que a hibridez da carta é também devida a aqueles para quem a missiva se dirige, os destinatários.

Diante dessa perspectiva os moldes textuais abandonam a leitura imanente que por ventura possa ser feita de um texto, e, portanto, alargam sua perspectiva considerando-se que se constrói mediante fatores externos a letra.

Se digo que em parte a hibridez da carta é concebida de acordo com o destinatário, no sentido de que cada um requer que a missiva adote características para a construção do diálogo, é por entender que, em contrapartida, ela também é fruto da época em que a carta é escrita e da época em que é lida.

A fronteira que se erige a partir das diferenças elencadas é basilar para desenvolver um modo, ou antes, uma perspectiva de ler a carta. Em síntese, ler no século XXI cartas, especialmente aquelas escritas por escritores, necessita considerar um determinado conceito de fronteira que é geográfico e epistemológico.

A fronteira como espaço a partir do qual algo começa a se fazer presente, como uma teorização da carta, por exemplo, coaduna com fala de Martin Heidegger que Homi Bhabha utiliza como epígrafe para iniciar seu O local da cultura (2013) e com a metáfora fornecida por Brigitte Diaz, "pensamento nômade".

Ler e estudar as cartas percebendo-se de algumas de suas fronteiras é perceber que, como indica Brigitte Diaz que as cartas são textos híbridos e escapam a identificações, vagando por entre gêneros. O nomadismo epistolar é o que se pode chamar de antigênero, por excelência, visto que é: “[...] rebelde a qualquer alistamento em esquemas de pensamento e de expressão pré-calibrados" (DIAZ, 2016, p. 50 - 51) e que portanto: “[...] não se pode mais então falar verdadeiramente de gênero epistolar, por parecer que esse gênero devorou todos os outros" (DIAZ, 2016, p. 50).

O estudo das cartas ao se deparar com a característica hibrida e fronteiriça do texto epistolar reconhece, por conseguinte, que: “O estatuto genérico vago da carta abre para todos os horizontes epistemológicos. Porque zomba dos discursos constituídos, torna-se o instrumento ideal de um saber vivo" (DIAZ, 2016, p. 46).

Reconhecer que a correspondência amplia os horizontes epistemológicos por não ser vinculada a tão somente um gênero é reconhecer que a carta é portadora de novas e Volume 18

Número 40 
outras epistemologias, e também, que ela é uma forma de conhecimento, nem melhor ou pior, visto que uma leitura polarizadora não abarcaria as diferenças, se comparadas com outras formas de comunicação.

Pensar por meio do raciocínio binarista de certo possui o "mérito" de corroborar um modelo de pensamento e de fazer cientifico característicos da razão ocidental e, de um determinado tipo de saber estipulado pela categorização. Mas, na esteira de Bhabha questiona-se:

Será preciso sempre polarizar para polemizar? Estaremos presos a uma politica d combate onde a representação dos antagonismos sociais e contradições históricas não podem tomar outra forma senão a do binarismo versus politica? (BHABHA, 2013, p. 47).

Polarizar as reflexões tecidas sobre a carta é caminhar em direção ao conceito de teoria e a uma percepção que aloca as correspondências em lugares estanques e, portanto, percebe o estudo sobre cartas a partir de uma ótica linear histórica que imputa ao objeto uma abordagem puramente textual e imanente.

A proposta crítica de ler as cartas a partir do duplo conceito de fronteira deriva-se da leitura, em conjunto, das cartas de Fernando Sabino. As correspondências do escritor, aos olhos do crítico e do leitor, transparecem diversas características e diferenças entre si. Para uma melhor percepção do que digo trago, de modo subsequente, um trecho de cada volume principal de cartas do autor mineiro, Cartas a um jovem escritor (1981), Cartas perto do coração (2001) e Cartas na mesa (2002):

O primeiro recorte diz respeito a carta que se seguiu como resposta

Belo Horizonte, 15-1-1942

Prezado Mário de Andrade,

Acabo de receber sua carta. Para mim ela vale mais do que tudo que falaram - ou poderiam falar - de "Os grilos".

Explico-me: há muito esperava sua opinião, no que ela pudesse me servir, com ansiedade incontida. Confesso que pensei nela antes da publicação do livro (e esta foi para mim apenas um meio de orientação, um marco, um ponto de partida). Pois bem - a orientação esperada partiu de você, com essa carta. É como se eu tivesse publicado o livro apenas para recebe-la.

(SABINO, 2003, p.).

O segundo trecho trata de uma carta escrita enquanto Fernando Sabino residia em Nova York, o texto em questão fora escrito em 10 de junho de 1946 e pertence ao livro Cartas perto do coração:

Volume 18

Número 40 
[...] Aqui na minha frente, na minha mesa do escritório, tem uma pilha de 1834 fichas me esperando para serem conferidas. São tão simpáticas, as fichinhas. Me esperam e sorriem burocraticamente: conhecem o meu triste fim. Sorrio também para elas, digo que esperem: agora estou indo para Seminarstrasse.

$[\ldots]$

Manuel Bandeira é um sujeito muito triste, Clarice. Também não me despedi de muita gente. Também me esqueci de muitas coisas no Brasil. Quando eu era menino, chupei uma vez tanta manga verde que fiquei doente de cama por três dias, faltei ao grupo, só vendo. Eu tinha um coelhinho chamado Pastoff. Um dia meu pai pegou o coelho e deu para um amigo, fiquei triste mesmo, chorei muito, papai foi muito mau. A coisa que mais gostava era no tempo de frio sair fumacinha da minha boca. Pipocas, Fernando! Clarice Lispector é uma coisa riscadinha sozinha num canto, esperando, esperando. Clarice Lispector só toma café com leite. Clarice Lispector saiu correndo no vento na chuva, molhou o vestido, perdeu o chapéu. Clarice Lispector sabe rir e chorar ao mesmo tempo, vocês já viram? Clarice Lispector é engraçada! Ela parece uma árvore. Todas as vezes que ela atravessa a rua bate uma ventania, um automóvel vem, passa por cima dela, e ela morre. Me escreva uma carta de sete páginas, Clarice.

(SABINO, 2011, p. 20).

O trecho final é de uma carta escrita no Rio de Janeiro, em 12 de março de 2017, e se encontra presente em Cartas na mesa:

$[\ldots]$

A editora Sabiá vai bem, mas tive que fazer uma intervenção de fato nas nossas finanças. Nada de grave - descuidamos um pouco, editamos mais do que podíamos, a rentabilidade foi pro beleleu, apesar do excelente faturamento. É não dar passo maior que as pernas, que a coisa vai.

Uma página, e nem comecei! Notícias rápidas: negócio de censura previa está com jeito de não pegar. A política continua podre, mas sempre há jeito de não se tomar conhecimento - a praia continua animada. A coisa grave são as torturas, atualmente oficializadas, baixaram uma cortina de silencio sobre o assunto e estão condenando quem divulgue. O Castelinho resolveu mandar brasa e já está incomodando o Governo com seus (ótimos) artigos pregando a volta à democracia. O Castelinho hoje é outro homem: lépido, fagueiro, uisquinho aqui, papinho animado (com elas) ali.

O Hélio, naquela mesma coisa. Reina um chove-não-molha desgraçado em relação ao caso dele, tudo como dantes no quartel D'Abrantes. O Paulinho continua sumido, mas bonzinho pela manhã, anda meio avariado "com estafa" (ressaca). O Casteja batendo pino, está numa hipocondria daquelas, tenho tentado animá-lo.

Escrevi uns contos - coisa de quem, não tem mais o que fazer - mandou um junto, diga o que acha e anote: como esse, posso escrever uns dez. Você já leu "L'envers et l'endroit" do Albert Camus Reli agora - um livr que é você que deveria ter escrito! Com exceção do prefácio (fraco), é aquela coisa - me diga o que acha, se ainda não leu, leia hoje, se não tem, compre correndo, e trate de escrever (ainda hoje) o seu.

$[\ldots]$

Volume 18

Número 40 
A onda por aqui é moralizante: andaram censurando até um pôster do David de Miguel Ângelo. Mas a minissaia continua. Deus seja louvado, e os biquínis também [...].

(SABINO, 2002, p. 296 - 298).

Articular na diferença as cartas em parte reproduzidas acima é entender que o missivista Fernando Sabino se valerá de diferentes estratégias a serem construídas de acordo com o destinatário ao qual se dirige, ou seja, se na primeira carta o autor se remete a Mario de Andrade assumindo o papel de pupilo e discípulo, na segunda carta o tom já é mais ameno e notamos certo trabalho de ficcionalização, já na última carta, esta dirigida aos amigos de Minas, o tom empregado é mais descontraído ao mesmo tempo em que Sabino se atenta para o momentos histórico vivido (ditadura militar). Pensar, como pontuado, para além da letra é, de carta forma, praticar o que pontua Homi Bhabha:

O que é teoricamente inovador e politicamente crucial é a necessidade de passar além das narrativas de subjetividades originárias e iniciais e de focalizar aqueles momentos ou processos que são produzidos na articulação de diferenças culturais (BHABHA, 2013, p. 20).

Quiçá uma teorização epistolográfica como a que aqui propomos emerja de sua própria estrutura. O conhecido "P.S" que está presente em muitas missivas deriva do latim "post scriptum" (despois da escrita) e lido a partir da perspectiva do século XXI bem pode assinalar o tardio nascimento da crítica epistolar.

O que vem depois da escrita, como indica a rubrica "PS", somente poderia ser sua teorização, uma vez que após o auge da carta, em forma de romance ou sob a forma documental, e com a emergência de outras formas de comunicação, como o email (eletronic mail - correio eletrônico), tornou-se inevitável uma perspectiva, não somente pós, mas também além da letra, em outras palavras, indisciplinar.

Dessa forma, o título dessa seção “O AQUÉM TEÓRICO, O ALÉM DA ESCRITA”, sintetiza a ideia de uma teorização epistolográfica ao indicar, em sua rubrica, que a empreitada, se guiada pelo moldes acadêmicos, está aquém da teoria (), mas enquanto teorização está para além da escrita.

Foi necessário o "fim da era epistolar" (muitos preferem falar, como sobre a Teoria e a Literatura, em morte) para que estudos sobre cartas de escritores se iniciassem, dessa forma a crítica epistolar (pelo menos na área de Letras) é, desde seu início, tardia. Com isto quero pontuar não que o estudo epistolar é ultrapassado, mas ressaltar uma característica importante sobre as cartas: a de que sua pratica, pelo menos como a 
conhecemos, esmoreceu junto ao século XX (o que não quer dizer que no século XXI não existam mais remetentes e destinatários) para que sua crítica nascesse no novo milênio.

No sentido da discussão proposta a carta não é somente campo propicio para discussões epistemológicas, como de fato o foi para a psicanalise (DERIDA, 2001) e para o modernismo brasileiro (ver as cartas de Mário de Andrade), mas as cartas são, em si, uma forma de conhecimento (epistemologia) anfíbia e hibrida. O fato de ainda não ser devidamente reconhecido "talvez" se deva a sua polimorfia.

Entender a carta como teorização é entender que trata-se de um texto concebido não no seio da academia, e muito menos a ela destinado (ainda que universidades do mundo inteiro se dediquem ao seu estudo). Mas, sobretudo, trata-se de um texto (tecido) que emerge de um bios e, portanto, não pode ser moldado como mercadoria teórica.

\section{REFERÊNCIAS}

ANDRADE, Mário de; SABINO, Fernando. Cartas a um jovem escritor e suas repostas. Rio de Janeiro: Record, 2003.

BHABHA, Homi. O local da cultura. Trad. Myriam Ávila. Belo Horizonte: Editora UFMG, 2010. (Humanitas).

DIAZ, Brigitte. O gênero epistolar ou o pensamento nômade: formas e funções da correspondência em alguns percursos de escritores no século XIX. Trad. Sandra Ferreira. São Paulo: EDUSP, 2016.

LISPECTOR, Clarice; SABINO, Fernando. Cartas perto do coração. Rio de Janeiro: Record, 2011.

MIGNOLO, Walter. Histórias locais/projetos globais: colonialidade, saberes subalternos e pensamento liminar. Trad. Solange Ribeiro de Oliveira. Belo Horizonte: Editora UFMG, 2003. (Humanitas).

SABINO, Fernando. Cartas na mesa. Rio de Janeiro: Record, 2002.

SOUZA, Eneida M. de. Janelas indiscretas: ensaio de crítica biográfica. Belo Horizonte: Editora UFMG, 2011. 